\title{
Mobilização comunitária e educação ambiental na ampliação do sistema de esgotamento sanitário do município de Ponta Porã-MS
}

\author{
Community Mobilization and Environmental Education in the Enlargement of the Sewage \\ System of Ponta Porã-Ms City
}

Movilización Comunitaria y Educación Ambiental en la Ampliación del Sistema Sanitario del Municipio de Ponta Porã-MS

Dulcélya Mônica de Queiroz Souza, UNESP, Universidade Estadual Paulista "Júlio de Mesquita Filho" Programa de Pós-Graduação em Gestão e Regulamentação de Recursos Hídricos (PROFÁGUA), Brasil. monicaqsouza@hotmail.com

Liliane Lazzari Albertin

Professora Doutora da UNESP, Universidade Estadual Paulista "Júlio de Mesquita Filho" Programa de Pós-Graduação em Gestão e Regulamentação de Recursos Hídricos (PROFÁGUA), Brasil.

liliane@dec.feis.unesp.br 


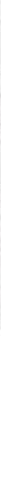

aspectos positivos e negativos, além de definição de novas ações visando cumprimento dos objetivos.

As reuniões comunitárias realizadas com a população (Figura 1), durante o desenvolvimento do projeto técnico social, possibilitaram a troca de experiências entre os moradores, isto resultou em aprendizado, pois possibilitou a população sanar dúvidas sobre o sistema de esgotamento sanitário. Todavia como em todo processo de mobilização comunitária, houve resistência da população em participar das reuniões, e esta indiferença dificultou a difusão das informações e orientações.

As micro reuniões (Figura 2), também foram extremamente importantes, pois despertaram o interesse da comunidade, por meio da interação com os vizinhos. No desenvolvimento do trabalho social foram realizadas 10 reuniões/micro reuniões atingindo um total de 118 participantes.

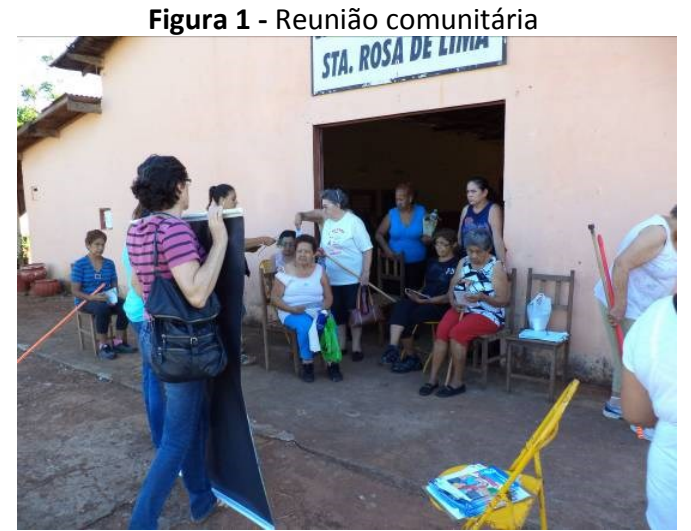

Fonte: ACERVO SANESUL, 2013.

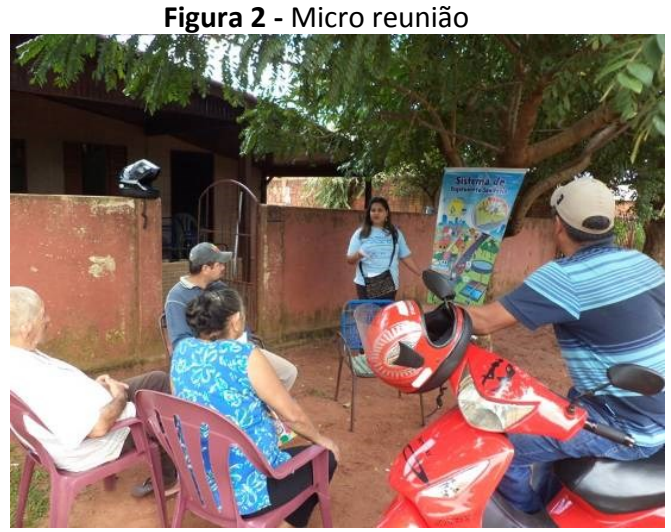

Fonte: ACERVO SANESUL, 2013.

A boa receptividade da maioria dos moradores favoreceu a abordagem na realização das visitas domiciliares (Figura 3), entretanto como em qualquer ação de mobilização houve resistência de algumas pessoas em receber os técnicos sociais, principalmente os moradores de maior poder aquisitivo e nível de escolaridade. No total foram atendidas 3.201 famílias.

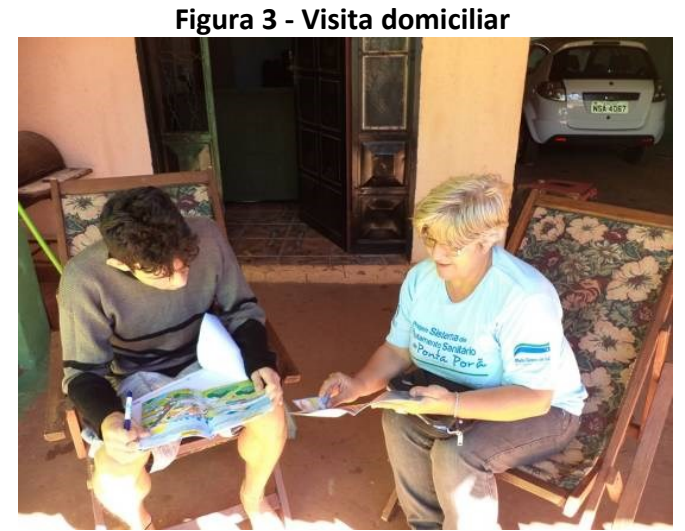

Fonte: ACERVO SANESUL, 2013.

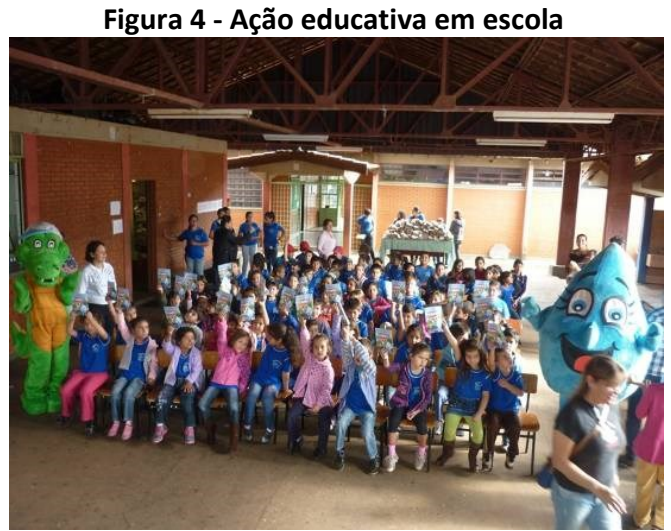

Fonte: ACERVO SANESUL, 2013. 


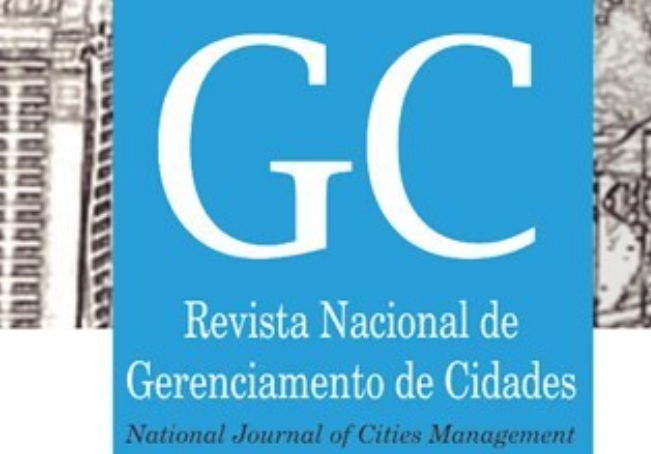

Quanto ao plantão social, apesar da existência de um local referenciado, não houve a sensibilização dos moradores, deste modo não contribuiu da maneira esperada para o processo de mobilização.

Nas ações educativas, com crianças e adolescentes nas escolas localizadas na área de projeto, foram atingidos 1.410 alunos. Houve envolvimento do corpo discente e docente, e o retorno dos alunos foi positivo, demonstrando o alcance dos objetivos propostos (Figura 4).

Quanto às campanhas, a realizada na primeira etapa foi denominada "Esgoto=saúde e qualidade de vida", a da segunda etapa, "Saia da fossa e se ligue no esgoto", e a execução das mesmas foram importantes para a socialização das informações.

De modo geral, o trabalho técnico social cumpriu os objetivos estabelecidos, pois de acordo com o resultado da pesquisa de satisfação aplicado junto aos moradores, no final da intervenção, tem-se que $86 \%$ afirmaram ter recebido orientação do técnico social sobre a implantação do sistema de esgotamento sanitário.

Cerca de $97 \%$ dos entrevistados afirmaram que receberam orientações por meio de visitas domiciliares e apenas $3 \%$ por reuniões, assim entende-se que embora sejam extremamente importantes, esta modalidade não é prática comum da população.

Também foram questionados sobre a importância do sistema de esgotamento sanitário, sendo que $100 \%$ avaliaram como muito importante, $100 \%$ também acharam importante o bairro ser contemplado com rede coletora e ao mesmo tempo informaram que irão proceder a ligação a rede.

Portanto o trabalho executado contribuiu para a consciencia crítica da população e instigou a mudança de comportamento avançando na reflexão crítica diante de investimentos estruturais.

\section{CONCLUSÃO}

As reuniões e micro reuniões proporcionaram a população o compartilhamento de opiniões e além da sensibilização para formulação de um novo conceito de sustentabilidade e responsabilidade social. A técnica de abordagem por meio das visitas domiciliares também foi eficaz no cumprimento dos objetivos, e proporcionou aos moradores ampliar os conhecimentos sobre o sistema de esgotamento sanitário e permitiu a integração da equipe técnica com a população beneficiária.

Todavia este sucesso não foi observado no desenvolvimento do plantão social, que acabou por não contribuir para a mobilização dos beneficiários. Este desinteresse foi observado em outros locais, principalmente quando não há exigência de comparecimento ao local para recebimento de benefícios.

As ações educativas com crianças e adolescentes foi um recurso atrativo, instigou a reflexão sobre as ações sustentáveis a favor do meio ambiente, contribuindo para a formação de consciência crítica e construção de uma sociedade sustentável e não descartável.

Por fim, através das atividades desenvolvidas foi possível transmitir informações e orientações, provocar discussões de temas transversais que estão interligados com as ações desenvolvidas pelo trabalho social e também elevar o nível de conhecimento dos moradores promovendo a sustentabilidade do empreendimento e colaborando para o prolongamento da vida útil da rede coletora. 
